\title{
Distribution and pathogen identification of cassava brown leaf spot in China
}

\author{
Y.L. Pei, T. Shi, C.P. Li, X.B. Liu, J.M. Cai and G.X. Huang \\ Key Laboratory of Integrated Pest Management on Tropical Crops, \\ Ministry of Agriculture, Environment and Plant Protection Institute, \\ Chinese Academy of Tropical Agricultural Sciences, Haikou, Hainan, China \\ Corresponding author: G.X. Huang \\ E-mail: hgxiu@vip.163.com / shitaofly2008@hotmail.com
}

Genet. Mol. Res. 13 (2): 3461-3473 (2014)

Received January 28, 2013

Accepted July 31, 2013

Published April 30, 2014

DOI http://dx.doi.org/10.4238/2014.April.30.7

\begin{abstract}
Cassava brown leaf spot surveys were conducted in the main cassava plantation areas of China between 2007 and 2012 in order to understand the distribution of the disease. Cassava plants were damaged by the disease to different degrees in most of the survey sites. Samples were collected and seven strains were isolated from lesions. The mycelium-breaking plus black light induction method was applied for sporulation. Microconidia were formed by means of fragmentation on artificial medium plates. When the leaf was stabbed and inoculated with conidia solution, similar symptoms were formed 14 days later. Morphological characteristics of the specimens and conidia were similar to descriptions of Passalora henningsii infection. The internal transcribed spacer (ITS) regions of rDNA were obtained with primer pair ITS1/ITS4 and deposited in GenBank, which differed by three base pairs from that of the P. henningsii isolate (AF284389). The ITS sequences of related species were downloaded from the NCBI database, and phylogenetic analysis showed that the sequences originating from our strains clustered in the same clade as the AF284389 isolate. Biological characteristics were evaluated in two strains from different sites, which indicated that the optimum conditions for mycelia growth were a temperature of $26^{\circ}$ to
\end{abstract}


$28^{\circ} \mathrm{C}$, carrot agar medium, $\mathrm{pH}$ 6, and continuous dark; cassava leaf juice added to malt extract and cassava leaf juice added to potato dextrose agar were the best media for conidia production. The optimal and lethal temperatures for macroconidia germination were $26^{\circ}$ to $28^{\circ} \mathrm{C}$, and $60^{\circ} \mathrm{C}$ for $10 \mathrm{~min}$, respectively.

Key words: Cassava; Pathogen identification; Passalora henningsii

\section{INTRODUCTION}

Cassava (Manihot esculenta Crantz.) is one of the most important tropical tuber crops in the world, and is widely cultivated in Africa, Latin America, and South East Asia. Approximately 500 million people depend on this root crop for food, and several million Asian farmers grow it for industrial markets (CIAT, 1976). In 2013, total tuber production was approximately 255 million tonnes (FAO, 2013). Cassava was first introduced to China around 1820. Cassava is currently widely cultivated in southern China and its cultivated area is continually expanding, reaching 393,000 ha in 2012. In China, approximately $70 \%$ of cassava tubers are used for starch and ethanol production, which represents an important economic resource for the local area. In 2005, China became the largest cassava importing country. Since cassava production is not selfsufficient, development of the cassava industry in China is urgently required to meet the high demand. Therefore, the Ministry of Agriculture of China planned to increase the cultivated area to 1,000,000 ha. Guangxi Province is currently the largest planting area, followed by Guangdong, Hainan, and Yunnan Provinces.

Brown leaf spot (BLS), caused by Passalora henningsii infection, is one of the most important fungal diseases of cassava, and is found in almost all the main plantation areas (Jameson, 1970; Lozano and Booth, 1974; Wydra and Verdier, 2002). This disease was first found in east Africa in 1885, and later occurred in India in 1904, and in the Philippines in 1918 (Maini et al., 1978; Palomar and Martinez, 1988), and ultimately spread to Brazil, Panama, Columbia, Ghana, and other countries by the 1970s (Toller et al., 1959; Castaño, 1969; Ayesu-Offei and AntwiBoasiako, 1996). The disease results in leaf yellowing and subsequent defoliation, decreasing the tuber output, resulting in yield losses of more than 10\% (Terry and Oyekan, 1976; CIAT, 1976; Teri et al., 1984). Although BLS has been reported in China (Pan et al., 1998), little research has focused on this disease, and the occurrence of the pathogen has not yet been confirmed. In the present study, we confirmed the distribution and pathogen identification of the disease in China. The objectives of this study were: i) generally assess the degree and extent of harm induced by BLS, and ii) verify the pathogen and obtain data of its biological characteristics.

\section{MATERIAL AND METHODS}

\section{Disease survey}

BLS surveys were carried out in the main cassava plantation areas of China between 2007 and 2012; the geographical positions of these sites were determined by GPS. The prevalence of BLS and the specific cassava varieties were recorded at each site, including planting area and the percentage of diseased plants. 


\section{Pathogen isolation}

The pathogens were obtained from symptomatic cassava leaves in the following manner. The conidia were gently washed from characteristic lesions with sterilized water, and the final concentration of the conidial suspensions was adjusted to $10^{3}$ conidia $/ \mathrm{mL}$. Potatodextrose agar (PDA) medium plates containing $100 \mu \mathrm{g} / \mathrm{mL}$ ampicillin, kanamycin, and cephalothin were prepared. A $20-\mu \mathrm{L}$ conidia solution was evenly coated on the surface and cultured at $28^{\circ} \mathrm{C}$ for two days. When small colonies emerged, they were transferred to new PDA plates and cultured under the same conditions. The culture and morphological characteristics were observed 30 days later.

\section{Pathogenicity assays}

Pathogenicity was determined following Koch's criteria. After strains were single spore purified and cultured on PDA medium plates at $28^{\circ} \mathrm{C}$ for 30 days, mycelia were ground with approximately $5 \mathrm{~mL}$ sterilized water. The mycelia fragment suspensions were coated on the surface of new media plates. The plates with dried surfaces were cultured at $28^{\circ} \mathrm{C}$, irradiated under black fluorescent lamps (National: FL20S BL-B) for 15 days, and then the conidia on the surface were washed with sterilized water and adjusted to $10^{5}$ conidia $/ \mathrm{mL}$. Young, healthy, and fully expanded green leaves of cassava cultivar SC8, which were cultivated for two months, were surface-sterilized, punched with sterile needles, inoculated with $20 \mu \mathrm{L}$ conidia solution, and kept under humid conditions for $36 \mathrm{~h}$. Sterile water was used as a control. Leaves were observed every day until lesions formed.

\section{Morphological and culture characteristics}

Morphological examinations of strains and lesions were performed according to previously published methods. Leaves with lesions were maintained under moist conditions with free water to evaluate the sporulation of microconidia. The lesions were straight-cut and stromatas were observed. The conidia were washed from the lesions and colonies, observed, and measured.

\section{Internal transcribed spacer (ITS) sequencing and phylogenetic analysis}

All strains were cultivated in potato dextrose liquid medium under shaking at 180 rpm at $28^{\circ} \mathrm{C}$ for 20 days. Mycelia were collected by careful filtration, and genomic DNA was extracted with the cetyltrimethylammonium bromide (CTAB) protocol (Xu and Leslie, 1996). The primers ITS1/ITS4 were synthesized and the ITS regions of rDNA were obtained by polymerase chain reaction (PCR) amplification (Cooke et al., 2000). The sequences were identified by BGI-Shenzhen and deposited in the GenBank database.

In order to study phylogenetic relationship of the pathogen to other Passalora spp and genetically related genera, ITS sequences were obtained from Genbank, including those of Passalora spp, Cercospora spp, and Pseudocercospora spp (Table 1). Phylogenetic trees were constructed using maximum likelihood (ML) and Bayesian analyses of nucleotide sequences. The general time reversible (GTR) model with six substitution categories was determined to be the most suitable model with the Modeltest v3.6 software (Posada and Crandall, 1998), and 
was used for all subsequent nucleotide analyses. ML trees based on nucleotide sequences were inferred using PHYML v2.4.5 (Guindon and Gascuel, 2003) with an estimated rate distribution shape parameter and bootstrap consensus values calculated using 1000 replicates.

Table 1. Internal transcribed spacer (ITS) sequences.

\begin{tabular}{|c|c|c|c|c|c|}
\hline Strains & Species & Host & Location & Collector & $\begin{array}{l}\text { Accession } \\
\text { No. (ITS) }\end{array}$ \\
\hline - & Passalora henningsii & Cassava & Brazil & - & AF284389 \\
\hline - & Passalora & Bougainvillea spectabilis & Mexico & - & $H Q 231217.1$ \\
\hline CBS 113374 & Passalora caribensis & Chromolaena odorata & Jamaica & M.J. Morris & DQ676512 \\
\hline CBS 113375 & Passalora caribensis & Chromolaena odorata & Jamaica & M.J. Morris & DQ676513 \\
\hline CBS 113376 & Passalora caribensis & Chromolaena odorata & Cuba & S. Neser & DQ676514 \\
\hline CBS 113371 & Passalora sp & Chromolaena odorat & Mexico & M.J. Morris & DQ676517 \\
\hline CBS 113378 & Passalora sp & Chromolaena odorata & Jamaica & M.J. Morris & DQ676520 \\
\hline CBS 113382 & Passalora sp & Chromolaena odorata & USA & M.J. Morris & DQ676522 \\
\hline CBS 113384 & Passalora sp & Chromolaena odorata & Jamaica & M.J. Morris & DQ676524 \\
\hline CBS 113613 & Passalora sp & Ageratina adenophora & Guatemala & M.J. Morris & DQ676525 \\
\hline CBS 114418 & Cercospora apii & Apium graveolens & Italy & Meutri & AY840517 \\
\hline CBS116501 & Cercospora beticola & Beta vulgaris & Iran & A.A.Ravanlou & AY840528 \\
\hline ATCC32779 & Cercospora canescens & Vigna radiata & Taiwan, China & - & AY266164 \\
\hline - & Cercospora sorghi & Sorghum bicolor & Texas, USA & - & AF291707 \\
\hline - & Cercospora sorghi var. Maydis & Zea mays & Kenya & - & AF297232 \\
\hline CPC 12062 & Cercospora $\mathrm{sp}$ & Zea mays & KwaZulu-Natal, South Africa & P. Caldwell & DQ185071 \\
\hline CBS 117755 & Cercospora zeae-maydis & Zea mays & Indiana, USA & B. Fleener & DQ185072 \\
\hline CBS117760 & Cercospora zeae-maydis & Maize & Tennessee, USA & B. Fleener & DQ185077 \\
\hline CBS 118820 & Cercospora zeina & Zea mays & South Africa, KwaZulu-Natal & P. Caldwell & DQ185081 \\
\hline CBS 113366 & Pseudocercospora & & & & \\
\hline eupatoriella & Chromolaena odorata & USA & M.J. Morris & DQ676526 & \\
\hline CBS 113372 & Pseudocercospora & & & & \\
\hline eupatoriella & Chromolaena odorata & Jamaica & M.J. Morris & DQ676531 & \\
\hline CBS 113386 & Pseudocercospora & & & & \\
\hline$s p$. & Chromolaena odorata & Mexico & M.J. Morris & DQ676532 & \\
\hline CBS 111072 & Pseudocercospora sp & Eucalyptus pellita & Thailand & M.J.Wingfield & DQ303082 \\
\hline CPC 11654 & Pseudocercospora $\mathrm{sp}$ & Morus bombycis & Korea & H.D. Shin & DQ303086 \\
\hline CPC 11680 & Pseudocercospora $\mathrm{sp}$ & Ampelopsis brevipenduncula & Korea & H.D. Shin & DQ303088 \\
\hline CMW 22521 & Pseudocercospora $\mathrm{sp}$ & Eucalyptus camaldulensis & Thailand & K. Ramawong & DQ632690 \\
\hline CMW 22522 & Pseudocercospora sp & Eucalyptus E. camaldulensis hybrid & South East Vietnam & T.I. Burgess & DQ632691 \\
\hline CMW 22523 & Pseudocercospora $\mathrm{sp}$ & Eucalyptus & Irian Jaya, Indonesia & S. Sufaati/P. Barber & DQ632693 \\
\hline CBS 122469 & Pseudocercospora longispora & Musa cv.Pisang Mas AA & Malaysia & - & EU514284 \\
\hline CBS 122468 & Pseudocercospora $\mathrm{sp}$ & Ravenala madagascariensis & India & - & EU514286 \\
\hline CPHHN01 & Passalora henningsii & Cassava & Hainan, China & YueLing Pei & FR847944 \\
\hline CPHHN02 & Passalora henningsii & Cassava & Hainan, China & YueLing Pei & FR847945 \\
\hline CPHHN03 & Passalora henningsii & Cassava & Hainan, China & YueLing Pei & FR847946 \\
\hline CPHHN04 & Passalora henningsii & Cassava & Hainan, China & YueLing Pei & FR847947 \\
\hline CPHGX01 & Passalora henningsii & Cassava & Guangxi, China & YueLing Pei & FR847948 \\
\hline CPHGX02 & Passalora henningsii & Cassava & Guangxi, China & YueLing Pei & FR847949 \\
\hline CPHGX03 & Passalora henningsii & Cassava & Guangxi, China & YueLing Pei & FR847950 \\
\hline
\end{tabular}

$\overline{\mathrm{CBS}}=$ Centraalbureau voor Schimmelcultures, Utrecht, Netherlands; CMW = Tree Pathology Co-operative Program, Forestry and Agricultural Biotechnology Institute, University of Pretoria, South Africa; CPC = Culture collection of Pedro Crous, housed at CBS; The last seven ITS sequences were obtained in this study.

\section{Biological characteristics study}

Biological characteristics were determined by recording colony growth status under different conditions. Mycelia growth was measured under temperatures and $\mathrm{pH}$ values ranging from $16^{\circ}$ to $40^{\circ} \mathrm{C}$ and $\mathrm{pH} 4.0$ to 12.0 , respectively, and under continuous light, continuous dark, and alternating light and dark conditions. Mycelial growth and conidia production were measured under culture with various media, including PDA, potato-sucrose agar (PSA), corn agar (CMA), oat agar (OA), malt extraction (ME), carrot agar (CA), cassava leaf juice added to PDA (CPDA), cassava leaf juice added to ME (CME), and V8 juice (commercially mixed juice derived from eight kinds of vegetables: $200 \mathrm{~mL} 2 \mathrm{~g} \mathrm{CaCO}_{3}, 15 \mathrm{~g}$ agar, $20 \mathrm{~g}$ cassava leaves, and water to 1000 
$\mathrm{mL}$ ). The germination ratio and lethal temperature of mature conidia were evaluated under different temperatures ranging from $4^{\circ}$ to $40^{\circ} \mathrm{C}$ and at $50^{\circ}, 55^{\circ}, 60^{\circ}$, and $65^{\circ} \mathrm{C}$, for $10 \mathrm{~min}$ each.

\section{RESULTS}

\section{Distribution, pathogen isolation, and purification of BLS}

Twenty-six main cassava plantations in China were investigated between 2007 and 2012, and BLS was found at most of them. The major results, including investigation location, time, cassava variety, occurrence degree, and the serial number of the isolated strains are listed in Table 2. The survey results showed that BLS was the most common fungal disease of cassava in China. BLS always occurred in plantations located in areas with high temperatures. Usually, the cassava was planted in March and April, and BLS appeared in May, with a peak period of infection observed from August to October. The lesions initially appeared on the lower leaves, and then diffused to surrounding and upper leaves. Initial symptoms were small, dark green spots on the abaxial leaf surface, and two days later, the spots appeared on the adaxial surface, enlarged, and then grayish water-immersion lesions formed. Finally, these lesions became brown due to disease progression. Typical lesions were characterized based on angular, uniform brown spots on both sides of the leaves, and the margins of the spots were well defined and dark (Figure 1). In some cases, parts of the small veinlets adjacent to the spots were also dark.

The samples were collected and seven strains were obtained in our study, four came from Hainan province and the other three came from Guangxi province. After the isolates were cultured on PDA plates for 30 days, conidial suspensions were prepared and purified by single conidium isolates.

\section{Pathogenicity assays, morphological, and culture characterization}

Once the conidial solutions were inoculated for 14 days, similar symptoms appeared on the leaves of all seven strains (Figure 2). The pathogen was reseparated, and similar colonies and conidia were obtained.

These strains grew very slowly on PDA plates, reaching $14.3 \mathrm{~mm}$ in diameter by day 30 . The colony surface was light grey and villiform with compact mycelium and unsmooth margins (Figure 3). The CPHHN02 strain was selected for morphological and culture characterization. When the lesion was straight-cut, stromata could be observed under the epidermis, which were subspherical and brown and 18-50 $\mu \mathrm{m}$ in diameter (Figure 4). Conidiophores fasciculately developed on the stromata, which were straight or slightly curved, light grey-brown in color, unbranched, conical at the apex, and measured 16.5-57.5 x 3.5-6.0 $\mu \mathrm{m}$. New conidia formed on the apex of conidiophores, which were light grey in color (Figures 4 and 5). The macroconidia were light grey-brown, cylindrical, straight or slightly curved, blunt round at the apex, blunt round, or obconic at the base, with two to nine septates, and measured 20.1-80.4 x 5.3-7.4 $\mu \mathrm{m}$ (Figure 6). The macroconidia features on media plates were consistent with those on the lesions of leaves. The microconidia were not sporulated on the lesions that were kept humid, and were formed on the colony by means of fragmentation of the macroconidia. The microconidia were cylindrical, with no septates, and measured 8.3-19.4 x 3.4-7.1 $\mu \mathrm{m}$ (Figure 7). 


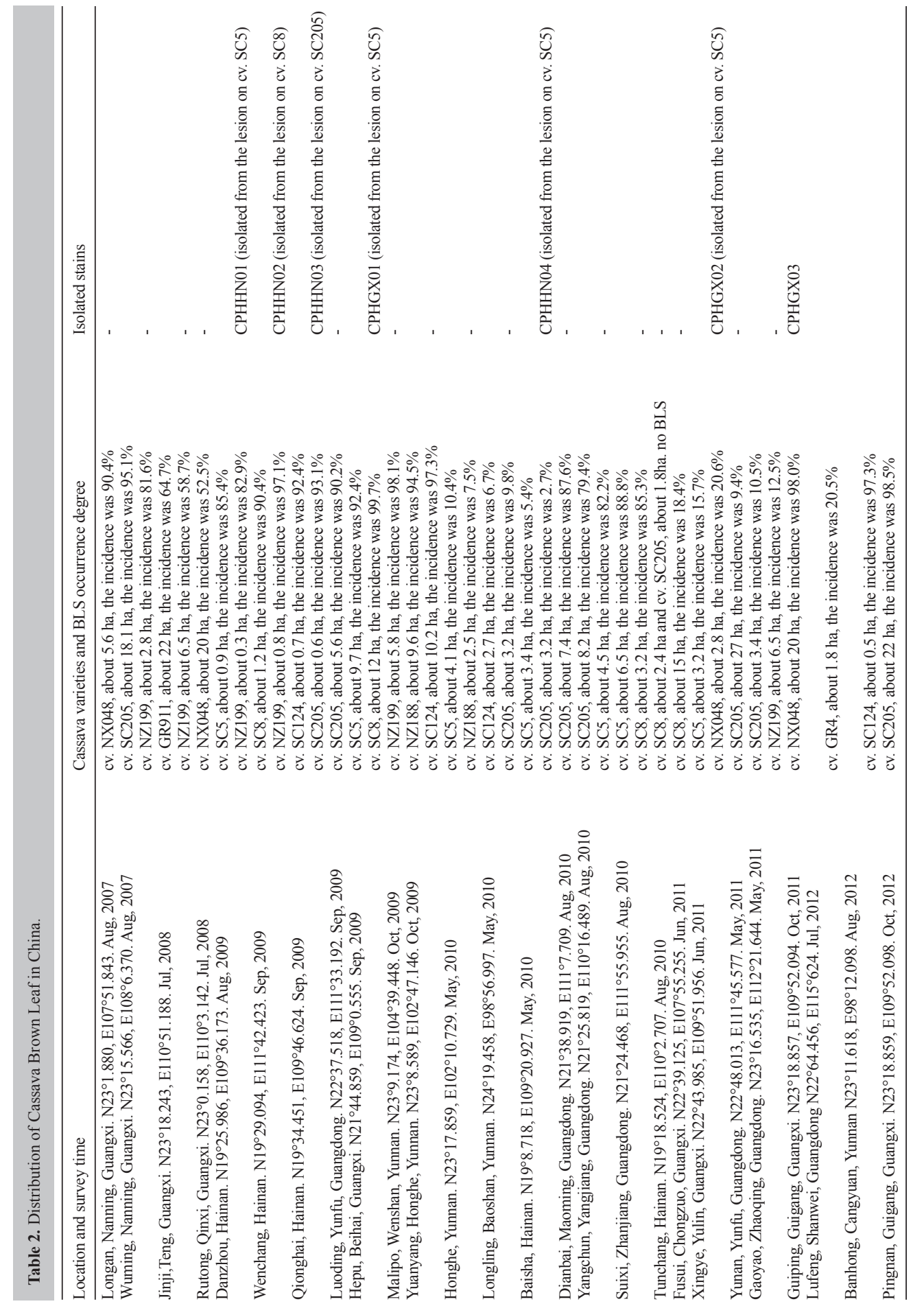




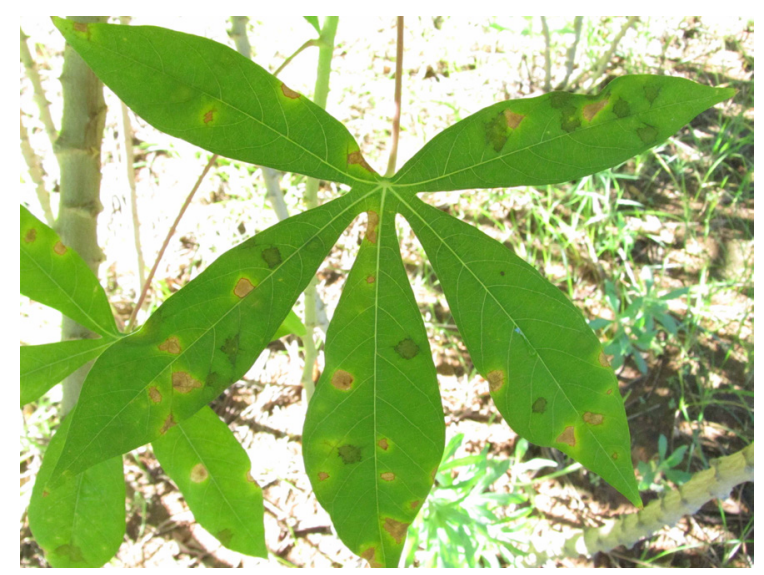

Figure 1. Disease leaf of BLS on cv.8 in plantation.

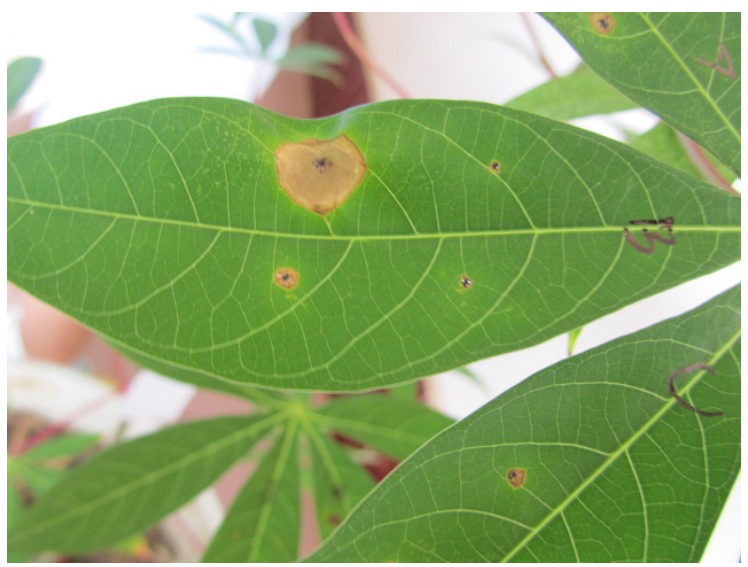

Figure 2. Pathogenicity of CPHHN02 on cv. SC8. Left = treatment; right $=\mathrm{CK}$.

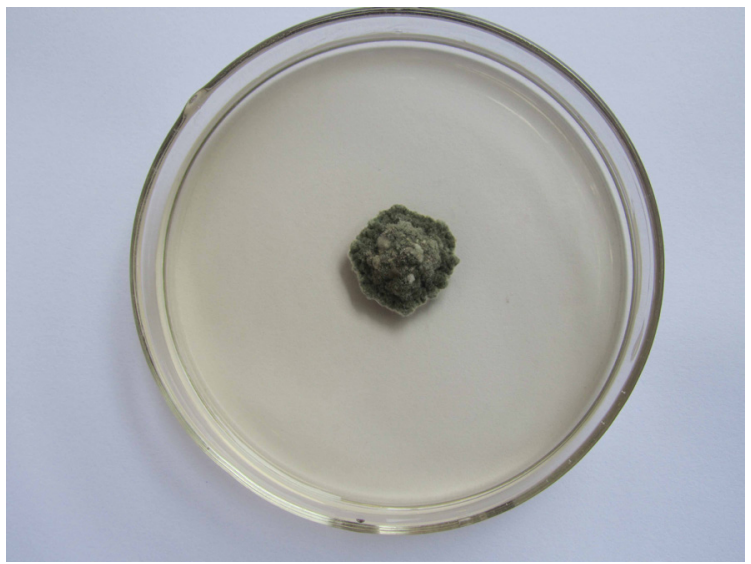

Figure 3. Colony of CPHHNO2 on PDA. 


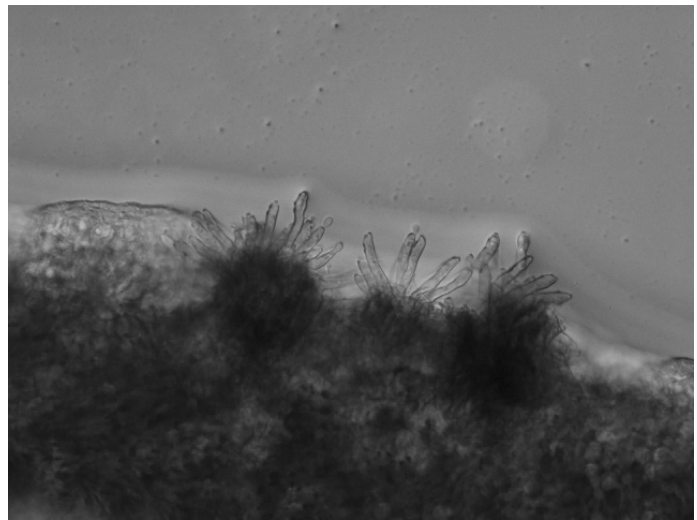

Figure 4. Stromatas and conidiophores of CPHHN02.

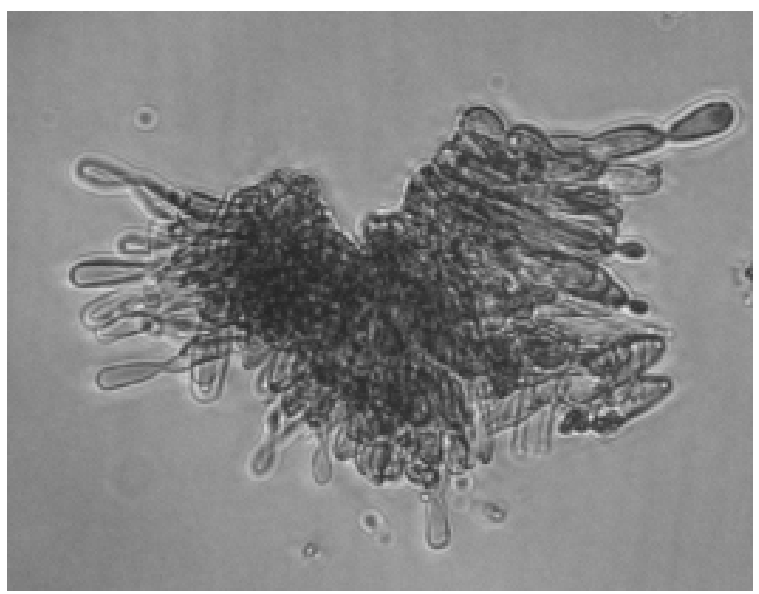

Figure 5. Fasciculate conidiophores and newborn conidia of CPHHNO2.

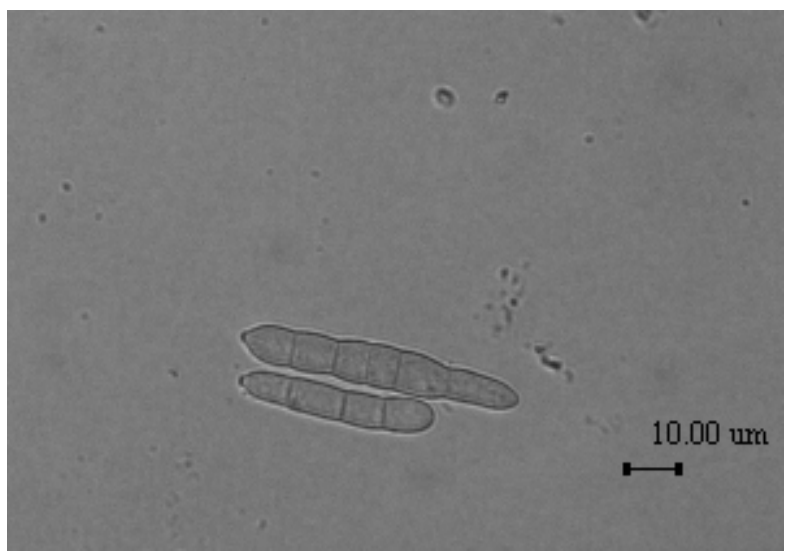

Figure 6. Macroconidia of CPHHN02. 


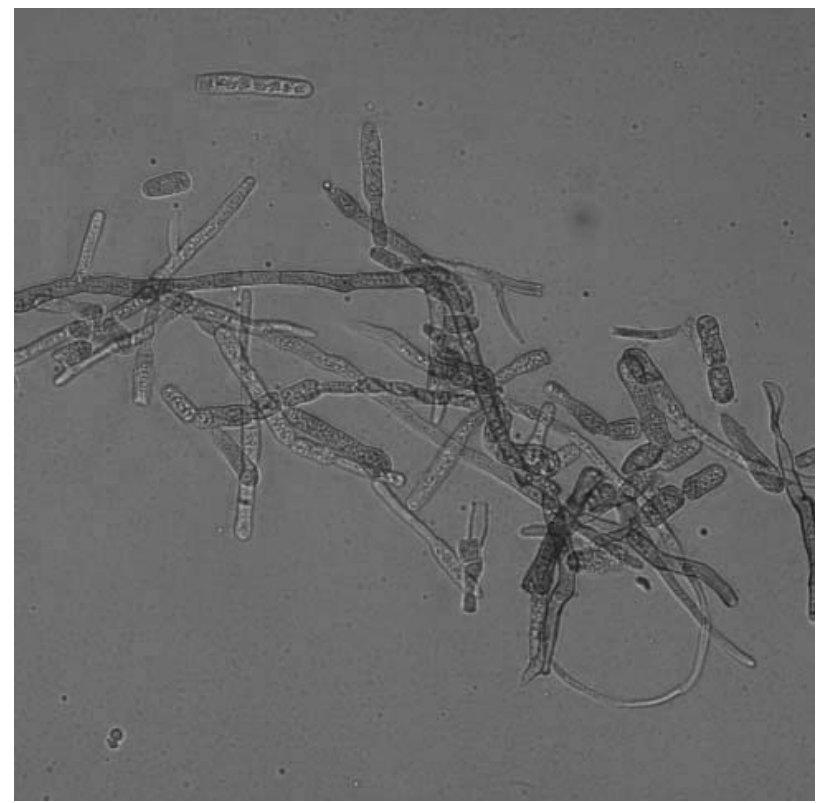

Figure 7. Microconidia formed by means of fragmentation of the macroconidia.

The colony characterization and microscopic examination of the other six strains were similar to those of CPHHN02, which is consistent with reports of $P$. henningsii (Guo and Liu, 2003; Ayesu-Offei and Antwi-Boasiako, 1996).

\section{ITS sequencing and phylogenetic analysis}

The genomic DNA of seven strains was extracted, and the primer pair ITS1/ITS4 was used for PCR amplification, which generated amplification products of $0.5 \mathrm{~kb}$ in length. Sequencing results showed that the length of all seven sequences was $473 \mathrm{bp}$; these sequences were deposited in GenBank and accession numbers are listed in Table 1. Five sequences (obtained from CPHGX01, CPHGX02, CPHHN01, CPHHN02, and CPHHN04) were identical, and the sequence obtained from CPHHN03 had one nucleotide substitution in which a $\mathrm{T}$ was replaced with $\mathrm{C}$ on locus 447, while the sequence obtained from CPHGX03 replaced a $\mathrm{C}$ with a $\mathrm{T}$ at locus 369. The overall identity of these seven sequences was $99.94 \%$. Comparison with sequences available in the GenBank database revealed that the current ITS sequence differs by three base pairs from that of $P$. henningsii (AF284389), which was a strain isolated from cassava (Inglis et al., 2001).

Using a Bayesian phylogenetic method, we estimated the phylogeny and divergence times of several Passalora spp, Cercospora spp, and Pseudocercospora spp (Figure 8). All Passalora spp from cassava showed high homology with an identity of $99.87 \%$, and they had two specific sequence combinations from locus 20 to 25 (with bases $\mathrm{T}$ and $\mathrm{C}$ at the two loci, respectively) and locus 407 to 424 (with bases $\mathrm{C}$ and $\mathrm{T}$ at the two loci, respectively), which differed from other Passalora spp. All Passalora spp isolated from different hosts clustered in the same clade (72\% bootstrap support), which comprised one of the two distinct clades in the phylogenetic tree, whose 
identity was $97.49 \%$. The second clade (100\% bootstrap support) contained a Cercospora spp cluster (100\% bootstrap support) and a Pseudocercospora spp cluster ( $85 \%$ bootstrap support), which had branch lengths of 0.039 and 0.018 , respectively.

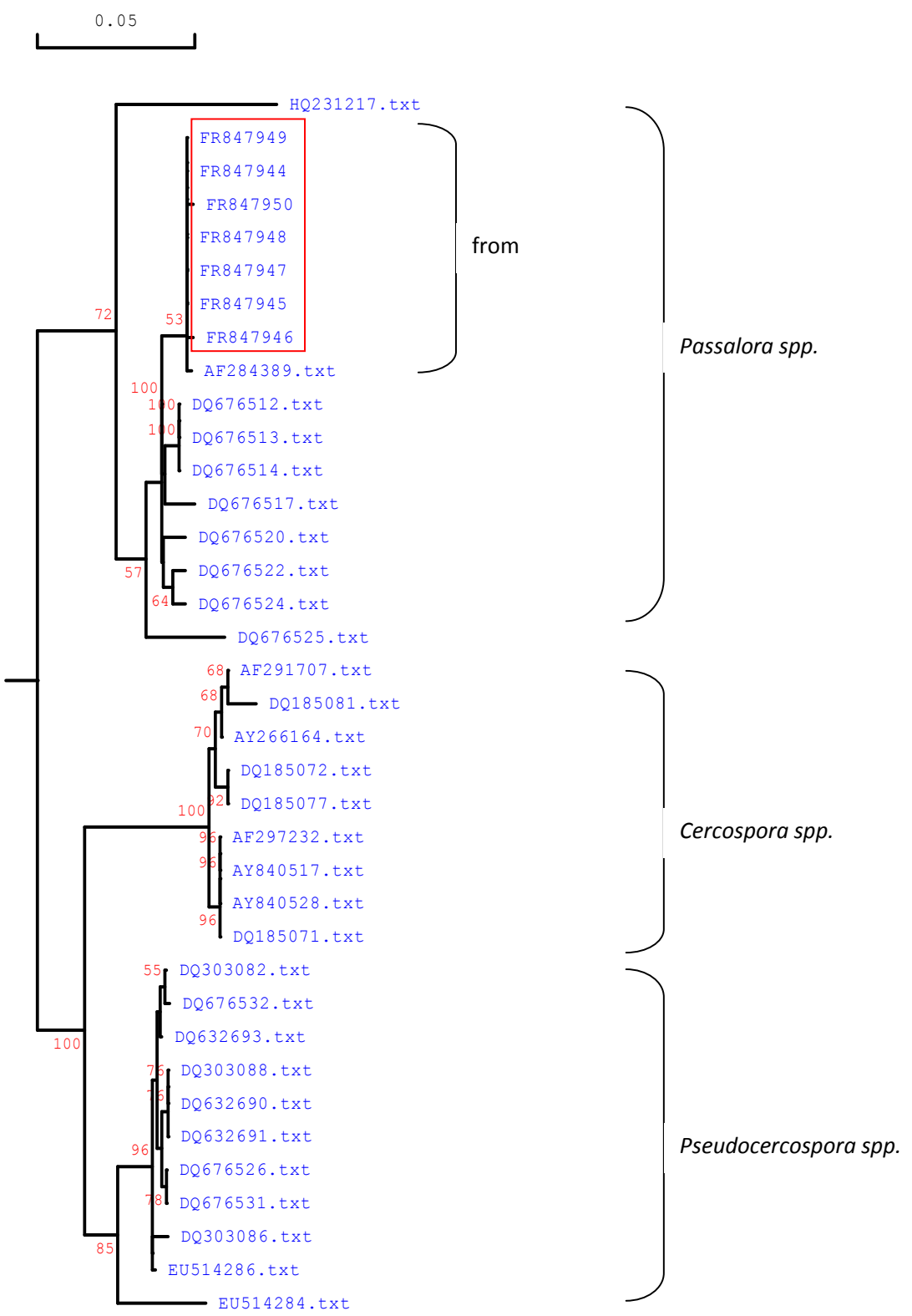

Figure 8. Phylogenetic trees obtained from the ITS sequence data of some Passalora spp, Cercospora spp, and Pseudocercospora spp. The isolates we obtained are in red pane. The scale bar shows a single change, and bootstrap support values from 1000 replicates are shown at the nodes. 


\section{Biological characteristics study}

Two strains of CPHHN02 and CPHGX01 were selected for the biological characteristics study. The optimal conditions for mycelial growth were determined to be a temperature of $26^{\circ}$ to $28^{\circ} \mathrm{C}$, CA medium, $\mathrm{pH}$, and continuous dark. Two kinds of conidia, including macroconidia and microconidia, were formed on the nine types of media plates. Conidia production was largest on CME and CPDA compared to the other media. The optimum temperatures and lethal temperature for macroconidia germination were $26^{\circ}$ to $28^{\circ} \mathrm{C}$ and $60^{\circ} \mathrm{C}$ for $10 \mathrm{~min}$, respectively. Only a few microconidia formed on the artificial media by fragmentation of macroconidia, indicating that the optimal and lethal temperature determinations for microconidia were incomplete.

\section{DISCUSSION}

In China, BLS, Anthracnose, Bipolaris leaf spot, and Corynespora cassiicola leaf spot are the major fungal diseases in cassava plantations (Hyder et al., 2010; Liu et al., 2010). These diseases often co-occur on leaves, and their symptoms are similar. Compared with BLS, Anthracnose lesions are easily enlarged and connected together, and the diseased leaf appears distorted and withered. Concentric ring lines are formed in the central area of lesions of Bipolaris leaf spot disease. The typical lesions of $C$. cassiicola leaf spot disease are dark brown or contain white papery centers delimited by dark brown rims surrounded by a yellow halo. Few studies on BLS have been carried out to date, and there has been no confirmation of its occurrence in China. Detailed and repeated investigations of BLS were conducted in China between 2007 and 2012, which covered the main cassava cultivation areas including Guangxi, Yunnan, Guangdong, and Hainan Provinces. Our study confirmed the presence of $P$. henningsii on cassava in China. BLS was found at most of the sites sampled, and our survey showed that it has become the most serious and widespread fungal disease. This is the first study describing the distribution and pathogen of BLS in China.

The pathogen of BLS was first named Cercospora henningsii in 1895, was later reclassified as Cercosporidium henningsii in 1976 (Deighton, 1976), and was ultimately named $P$. henningsii (Allesch.) R. F. (Castañeda and Braun, 1989). Morphological characteristics of the specimens and their conidia obtained in the present study were similar to previous descriptions of $P$. henningsii. ITS sequencing and phylogenetic analysis were in accordance with results of morphological observations. Some biological characteristics were confirmed in our study, and subsequent studies will focus on potential control methods and the pathogenic mechanism.

Borborua (1982) reported that $P$. henningsii could grow on PDA medium. Ayesu-Offei and Antwi-Boasiako (1996) suggested that $P$. henningsii was similar to obligate parasitic pathogens, which are very difficult to cultivate on artificial media. In the present study, the pathogen grew very slowly on eight kinds of media plates, which was similar to observations of previous studies. Although the tissue isolation method has been widely used for pathogen isolation, P. henningsii colonies are often covered by other microorganisms due to their significantly slow growth rates, and therefore, single conidium separation was compatibly used to isolate this kind of pathogen. Three kinds of antibiotics were added to medium plates in the present study, which yielded a better separation result. Six strains were obtained by single conidium separation, while only one strain was separated by tissue isolation. 
It has been suggested that only mycelium of $P$. henningsii could grow on medium plates and that conidia sporulate on CM medium plates with the addition of cassava leaf juice (AyesuOffei and Antwi-Boasiako, 1996; Silva et al., 1988). Similar results were obtained in our study. When the new mycelia of Magnaporthe grisea formed, several uniform conidia could be produced by broken treatment (Peng and Shishiyama, 1988). Usually, more fungal conidia can be obtained by ultraviolet treatment, whereas conidia of $P$. henningsii could not be obtained by mycelium-breaking or ultraviolet induction methods solely. Only when both measures were adopted jointly several conidia could be formed on media plates. During the whole sporulation course, the mycelium was broken and ultraviolet treatment was used; therefore, this method was named mycelium-breaking and ultraviolet induction. When the cassava leaf juice was added to the medium, more conidia were formed on the plate, which was consistent with results of previous studies.

Ayesu-Offei and Antwi-Boasiako (1996) reported abundant sporulation of lesions on cassava leaves and that microconidia were formed by means of budding and fragmentation of the macroconidia. Similar methods were applied in our study; however, no microconidia appeared on the lesions in the seven strains. Interestingly, microconidia grew on the colony by means of fragmentation of the macroconidia, which has not been reported in other studies.

The results of the present study provide a foundation for pathogenicity tests in future research. The cassava leaves were very delicate and often rot after five days under in vitro conditions; therefore, the leaves on plants are suitable materials for the test. By inoculating leaves with conidial solution, Ahmed et al. (2009) found that the spots appeared at the ninth day of culture, and the characteristic lesions with darker peripheries formed by the 13th day. In the present study, lesions did not form with mycelia, and a similar result was obtained using conidial solution.

\section{ACKNOWLEDGMENTS}

Research partially supported by the fund for Modern Agro-Industry Technology Research System (CARS-12-hnhgx) from the Ministry of Agriculture, China.

\section{REFERENCES}

Ahmed MB, Tomy P, Bolacaranda KK and Chandrakanth KK (2009). Scanning electron microscopy of the infection process of Cercospora henningsii on cassava leaves. J. Phytopathol. 157: 57-62.

Ayesu-Offei EN and Antwi-Boasiako C (1996). Production of microconidia by Cercospora henningsii Allesch, cause of brown leaf spot of cassava (Manihot esculenta Crantz) and tree cassava (Manihot glaziovii Muell.-Arg. Ann. Bot. 78: $653-657$.

Borborua A (1982). Two new leaf spot diseases of tuber crop in Assam. Indian J. Mycol. Plant Pathol. 12: 341.

Castañeda RF and Braun U (1989). Cercospora and allied genera of Cuba (I). Cryptogamic Bot. 1: 42-55.

Castaño A (1969). Leaf spots of Cercospora carribaea in cassava (Manihot utilisima Pohl) in the region of Barbasa (Antioquia). Agric. Trop. 25: 327-329.

CIAT (1976). Cassava Production Systems. Annu. Rep. Cali, Colombia.

Cooke DE, Drenth A, Duncan JM, Wagels G, et al. (2000). A molecular phylogeny of Phytophthora and related oomycetes. Fungal Genet. Biol. 30: 17-32.

Deighton FC (1976). Studies on Cercospora and allied genera. VI. Pseudocercospora Speg., Pantospora Cif. and Cercoseptoria Petr. Mycol. Pap. 140: 168.

FAO (2013). Food Outlook. Biannual Report on Global Food Markets. Rome.

Guindon S and Gascuel O (2003). A simple, fast, and accurate algorithm to estimate large phylogenies by maximum likelihood. Syst. Biol. 52: 696-704.

Guo Y-1 and Liu X-J (2003). Flora Fungorum Sinicorum. Vol. 20. Mycovellosiella, Passalora, Phaeoramularia. Science Press, Beijing. 
Hyder N, Wong FP, Koski A, Tisserat N, et al. (2010). First record of Bipolaris setariae from cassava in China. Plant Dis. 94: 919.

Inglis PW, Teixeira EA, Ribeiro DM, Valadares-Inglis MC, et al. (2001). Molecular markers for the characterization of Brazilian Cercospora caricis isolates. Curr. Microbiol. 42: 194-198.

Jameson JD (1970). Agriculture in Uganda. 2nd edn. Oxford University Press, Oxford, 116-276.

Liu XB, Shi T, Li CP, Cai JM, et al. (2010). First report of Corynespora cassiicola causing leaf spot of cassava in China. Plant Dis. 94: 916.

Lozano JC and Booth RH (1974). Disease of cassava (Manihot esculenta Crantz). Pans 20: 30-54.

Maini SB (1978). Quality Aspects of Cassava. In: Cassava Production Technology (Hrishi N and Nair RG, eds.). Central Tuber Crops Research Institute, Trivandrum, 73-74.

Palomar MK and Martinez MA (1988). Reaction of cassava plants to brown leaf spot infection. Ann. Trop. Res. 10: 1-8.

Pan YQ, Liang YD and Zhang KM (1998). China Tropical Crop Cultivation. China Agriculture Press, Beijing.

Peng YL and Shishiyama J (1988). Temporal sequence of cytological events in rice leaves infected with Pyricularia oryzae. Can. J. Bot.-Revue Canadienne De Botanique. 66: 730-735.

Posada D and Crandall KA (1998). MODELTEST: testing the model of DNA substitution. Bioinformatics 14: 817-818.

Silva MF, Cavalcanti MA, Lima DM and Poroca DM (1988). Influence of climatic factors and age of the plant on the occurrence of brown and white spots of cassava. Fitopatol. Bras. 13: 51-53.

Teri JM, Mtakwa PW and Mshana D (1984). Cassava Yield Losses from Brown Leaf Spot Induced by Cercosporidium Henningsii. Tropical Root Crops: Production and Uses in Afica (Terry ER, Doku EV, Arene OB and Mahungu NM, eds.). IDRC, Ottawa.

Terry ER and Oyekan JO (1976). Cassava diseases in Africa reviewed. Span 19: 116-118.

Toller RW, Cuellar R and Ferrer JB (1959). Preliminary Survey of plant diseases in the Republic of Panama. Plant Dis. Rep. 43: 1201-1203.

Wydra K and Verdier V (2002). Occurrence of cassava diseases in relation to environmental, agronomic and plant characteristics. Agric. Ecosyst. Environ. 93: 211-226.

Xu JR and Leslie JF (1996). A genetic map of Gibberella fujikuroi mating population A (Fusarium moniliforme). Genetics 143: 175-189. 